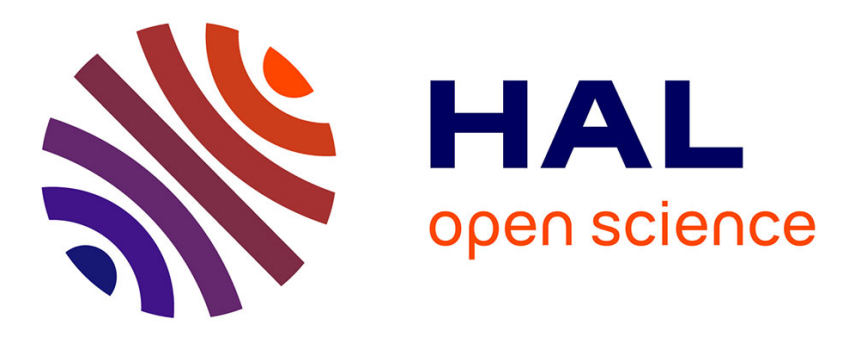

\title{
Distribution-free triple EWMA control chart for monitoring the process location using the Wilcoxon rank-sum statistic with fast initial response feature
}

Tokelo I Letshedi, Jean-Claude Malela-Majika, Philippe Castagliola, Sandile C Shongwe

\section{To cite this version:}

Tokelo I Letshedi, Jean-Claude Malela-Majika, Philippe Castagliola, Sandile C Shongwe. Distributionfree triple EWMA control chart for monitoring the process location using the Wilcoxon rank-sum statistic with fast initial response feature. Quality and Reliability Engineering International, 2021, 37 (5), pp.1996-2013. 10.1002/qre.2842 . hal-03504670

\author{
HAL Id: hal-03504670 \\ https://hal.science/hal-03504670
}

Submitted on 29 Dec 2021

HAL is a multi-disciplinary open access archive for the deposit and dissemination of scientific research documents, whether they are published or not. The documents may come from teaching and research institutions in France or abroad, or from public or private research centers.
L'archive ouverte pluridisciplinaire HAL, est destinée au dépôt et à la diffusion de documents scientifiques de niveau recherche, publiés ou non, émanant des établissements d'enseignement et de recherche français ou étrangers, des laboratoires publics ou privés. 


\title{
Distribution-free triple EWMA control chart for monitoring the process location using the Wilcoxon rank-sum statistic with fast initial response feature
}

Tokelo I. Letshedi ${ }^{1}$, Jean-Claude Malela-Majika ${ }^{1}$, Philippe Castagliola ${ }^{2}$, Sandile C. Shongwe ${ }^{1}$

\begin{abstract}
The exponentially weighted moving average (EWMA) control chart is a memory-type chart known to be more efficient in detecting small and moderate shifts in the process parameter. The double EWMA (DEWMA) chart is an extension of the EWMA chart that is more effective than the latter in the detection of small-to-moderate shifts. This paper proposes a new distribution-free (or nonparametric) triple EWMA (TEWMA) control chart based on the Wilcoxon rank-sum (W) statistic to improve the detection ability in the process location parameter. Moreover, a new fast initial response (FIR) feature is added to further improve the sensitivity of the new TEWMA chart. The performance of the proposed TEWMA chart with and without FIR features is compared to those of the existing EWMA and DEWMA W charts. It is observed that the TEWMA chart with and without FIR features is superior to the competing charts in most situations. A real-life illustration is provided to show the application and implementation of the new chart.
\end{abstract}

Keywords: Double EWMA chart; EWMA chart; Fast initial response; Nonparametric chart; Overall performance; Run-length; Triple EWMA.

\section{Introduction}

All production lines and service-rendering establishments are recommended to use statistical process monitoring (SPM) techniques. This will assist with producing or rendering high quality services or products that will meet needs of end users with low risk benefits. In applications where very little information is known about the underlying process, it is mostly advised to use nonparametric or distribution-free charts rather than the parametric ones. This is because they do not depend on any specific underlying distribution and they are generally in-control (IC) robust; see for instance, the arguments in Chakraborti and Graham ${ }^{1}$. For efficiency, memory-type control charts are usually used to detect small-to-moderate shifts of any process parameter. There are four different types of memory-type control charts in the SPM literature and these are: (i) Exponentially weighted moving average (EWMA) chart by Roberts $^{2}$, (ii) Cumulative sum (CUSUM) chart by Page $^{3}$, (iii) Generally weighted moving average (GWMA) chart by Sheu and $\mathrm{Lin}^{4}$, and (iv) Homogeneously weighted moving average (HWMA) chart by Abbas ${ }^{5}$. For more detailed studies or literature reviews on the latter memory-type schemes, see Hawkins and Olwell ${ }^{6}$, Ruggeri et $\mathrm{al}^{7}$, Mabude et $\mathrm{al}^{8}$, Nawaz and $\mathrm{Han}^{9}$, Abid et $\mathrm{al}^{10}$, Adegoke et $\mathrm{al}^{11}$ and Adeoti and Koleoso ${ }^{12}$. The focus of this paper is

${ }^{*}$ Corresponding author. E-mail: sandile@ tuks.co.za;

${ }^{1}$ Department of Statistics; College of Science, Engineering and Technology; University of South Africa; Pretoria; South Africa. ${ }^{2}$ Université de Nantes \& LS2N UMR CNRS 6004, Nantes, France. 
on improving the performance of the nonparametric EWMA-type charts to monitor the process location, especially during start-up period. Improving the performance of the EWMA-type control charts during start-up period has never been addressed for the nonparametric SPM context. For some recent contributions to nonparametric charts, refer for instance to Mukherjee et $\mathrm{al}^{13}$, Triantafyllou ${ }^{14}$, Chong et $\mathrm{al}^{15,16}$ and Shafqat et $\mathrm{al}^{17}$. Next though, a literature review of some related parametric research works are discussed and thereafter, the objective of this paper is outlined.

With an end goal to increase the responsiveness of the EWMA control charts to detect small shifts in a process mean, Shamma and Shamma ${ }^{18}$ proposed the double EWMA (DEWMA) control chart. Originally not aware of the latter paper, Zhang and Chen ${ }^{19}$ also studied the performance of the DEWMA chart to monitor the process mean; note though, there are additional aspects that were considered in the latter paper but absent in the former. Some additional studies on the DEWMA charts in different contexts can be found in Hong et $\mathrm{al}^{20}$, Alkahtani ${ }^{21}$, Teh et $\mathrm{al}^{22}$, Chao et $\mathrm{al}^{23}$ and, Alevizakos and Koukouvinos ${ }^{24}$. Based on latter publications, it is generally accepted that the DEWMA charts are more sensitive than EWMA charts for small-to-moderate shifts. For the nonparametric case, Karakani et al $^{25}$ showed that the DEWMA based on the exceedance statistic is superior to the EWMA one in detecting small shifts.

The focus of this paper is on the Wilcoxon rank sum statistic, denoted as $W$. Note that Li et $\mathrm{al}^{26}$ presented the EWMA $W$ chart with measurements utilizing a simple random sampling method. A while later, Malela-Majika and Rapoo ${ }^{27}$ presented the EWMA $W$ chart utilizing structured sampling techniques (i.e. based on rank set sampling method). More recently, Malela-Majika ${ }^{28}$ proposed a DEWMA $W$ chart which is shown to have better out-of-control OOC performance in detecting small-to-moderate shifts in the process location than the EWMA $W$ chart. Other discussions on control charts based on the $W$ statistic can be found in Tapang et $\mathrm{al}^{29}$, Malela-Majika and Rapoo ${ }^{30}$, Chakraborti and Graham ${ }^{1,31}$, Triantafyllou ${ }^{32}$, Mabude et $\mathrm{al}^{33}$, Tercero-Gomez et $\mathrm{al}^{34}$ and $\mathrm{Qiu}^{35}$.

Therefore, the main objective of this paper is to improve further on the research works by Li et $\mathrm{al}^{26}$ and Malela-Majika ${ }^{28}$, by proposing a new triple EWMA (TEWMA) $W$ chart to monitor the process location shifts and then compare its performance to that of EWMA and DEWMA $W$ charts. Note that there is no work in the SPM literature that addresses the use of TEWMA chart in a distribution-free context. To the best of authors' knowledge, Alevizakos et $\mathrm{al}^{36,37}$ investigated the performance of the TEWMA chart for monitoring the process mean 
and time between events, respectively. Moreover, Alevizakos et $\mathrm{al}^{36,37}$ compared the performance of each TEWMA chart against the corresponding EWMA and DEWMA charts, where it is observed that the TEWMA charts have better performance in most situations. Note though, for thorough derivations of the run-length properties of the TEWMA chart for any independent and identically distributed (i.i.d.) process, readers are referred to Alevizakos et $\mathrm{al}^{36}$.

The fast initial response (FIR), initially suggested in the SPM literature by Lucas and Crosier $^{37}$, is a head-start feature with similar (but, slightly more pronounced) positive effects compared to the time-varying control limits as it identifies issues during the start-up period. Thereafter, more researchers have used this enhancement technique at the start-up period of the monitoring process; see for instance Rhoads et $\mathrm{al}^{39}, \mathrm{Knoth}^{40}$ and $\mathrm{Lu}^{41}$. Note that Steiner ${ }^{42}$ proposed the use of a more formal multiplicative factor expression that yields tighter control limits at start-up and converges to the standard control limits as time increases. The basic FIR feature in Steiner ${ }^{42}$ is denoted as FIR in this paper. Later, Haq et $\mathrm{al}^{43}$, proposed a modified FIR (MFIR) feature which is shown to yield better OOC performance than the Steiner ${ }^{42}$, $\mathrm{S}$ FIR feature. Therefore, in addition to introducing the TEWMA $W$ chart; in this paper, a new improved MFIR (IMFIR) feature is incorporated to the TEWMA $W$ chart to improve its performance during the start-up period. For the sake of completeness and comparison purpose, the basic FIR and MFIR are also incorporated to the EWMA, DEWMA and TEWMA $W$ charts.

The rest of the paper is structured as follows: Section 2 provides some design background of the $W$ test statistic as well as the EWMA and DEWMA $W$ charts. The design of the proposed TEWMA $W$ charts with and without FIR features are discussed in Section 3. Section 4 gives an empirical performance of the proposed TEWMA $W$ chart and some comparisons against the EWMA and DEWMA $W$ charts. An illustrative example is given in Section 5 using reallife data. Finally, Section 6 provides some concluding remarks.

\section{The design of the EWMA and DEWMA $W$ charts}

\subsection{Wilcoxon rank sum test $(\mathrm{W})$}

Assume that $X=\left\{x_{i}, i=1,2, \ldots, m\right\}$ is an IC reference (i.e. Phase I) sample with unknown cumulative distribution function (c.d.f.), $F(x)$, and $Y_{t}=\left\{y_{t j}, t=1,2,3, \ldots ; j=1,2,3, \ldots, n\right\}$, simply denoted as $Y$, is a set of test samples with c.d.f. $G(y)$. The observations from the reference sample are assumed to be independent from each other and from the ones in the test 
samples. However, the distribution of the test samples is the same as the one of the reference sample with a difference in the location shift only. In other words, $F(x)=G(x+\delta)$, where $\delta$ represents the change (or shift) in the location parameter. Thus, when the process is incontrol (IC), $\delta=0$; hence, $F=G$. However, when $\delta \neq 0$, the process is said to be out-ofcontrol (OOC). Wilcoxon ${ }^{44}$ proposed the $W$ statistic by merging the $m$ reference observations with the $n$ observations of the $t^{\text {th }}$ test sample together and re-arranging all values of the $(n+m)$ observations in an ascending order. Let $\mathrm{A}=\left\{\mathrm{a}_{(1)}, \mathrm{a}_{(2)}, \ldots, \mathrm{a}_{(s)}, \ldots, \mathrm{a}_{(n+m-1)}, \mathrm{a}_{(n+m)}\right\}$ be the resulting ordered sample, where $a_{(s)}=x_{l}$ if $x_{l}$ is the smallest $l^{\text {th }}$ value from the newly formed sample $A$, also $a_{(s)}=y_{k}$ if $y_{k}$ is the smallest $k^{t h}$ value from $A$, this means that $s \in\{1,2, \ldots, n+m\}, k \in\{1,2, \ldots, n\}$ and $l \in\{1,2, \ldots, m\}$.

Let $I=\left\{a_{(1)}^{\prime}, a_{(2)}^{\prime}, \ldots, a_{(s)}^{\prime}, \ldots, a_{(m+n-1)}^{\prime}, a_{(m+n)}^{\prime}\right\}$ be the sample of the indicators where $a_{(s)}^{\prime}=1$ if $a_{(s)} \in X$ and $a_{(s)}^{\prime}=0$ if $a_{(s)} \in Y$. Then, at time $t$, the $W$ statistic is defined by

$$
W_{t}=\sum_{s=1}^{n+m}\left(i \times a_{(s)}^{\prime}\right)
$$

Assuming that there are no ties (i.e. duplicated values in the combined observations), the mean and the variance of the $W$ statistic are respectively given by (see for instance Li et $\mathrm{al}^{26}$ ):

$$
E\left(W_{t}\right)=\mu_{W}=\frac{m(m+n+1)}{2}
$$

and

$$
\operatorname{Var}\left(W_{t}\right)=\sigma_{W_{t}}^{2}=\frac{m n(m+n+1)}{12} .
$$

\subsection{The EWMA W control chart}

The EWMA $W$ chart was proposed by $\mathrm{Li}$ et $\mathrm{al}^{26}$ and its charting statistic is defined by

$$
E_{t}=\lambda W_{t}+(1-\lambda) E_{t-1}
$$

where $\lambda(0<\lambda \leq 1)$ is a smoothing parameter and $E_{0}=\mu_{W}$. After some basic algebraic manipulation, the mean and variance of (3) are respectively given by

$$
E\left(E_{t}\right)=\mu_{E}=\mu_{W}
$$

and

$$
\operatorname{Var}\left(E_{t}\right)=\sigma_{E_{t}}^{2}=\sigma_{W}^{2}\left(\frac{\lambda}{2-\lambda}\right)\left(1-(1-\lambda)^{2 t}\right)
$$

Hence, the upper and lower control limits of the EWMA $W$ chart are computed as follows:

$$
U C L_{t} / L C L_{t}=\mu_{E} \pm L_{E} \sigma_{E_{t}}
$$


where $L_{E}>0$ is the control limits coefficient which has to be calculated such that the attained IC $A R L\left(A R L_{0}\right)$ is close or equal to the pre-specified nominal $A R L_{0}$. Thus, the EWMA $W$ chart gives a signal if $E_{t}$ plots beyond the control limits.

\subsection{The DEWMA $W$ chart}

The DEWMA $W$ chart was proposed by Malela-Majika ${ }^{28}$ and its charting statistic is given by

$$
D_{t}=\lambda E_{t}+(1-\lambda) D_{t-1}
$$

where $E_{t}$ is as given in (3) and $D_{0}=\mu_{W}$. That is, the smoothing procedure is applied twice, i.e. the first smoothing is done in (3) and the second one is done in (6). After some basic algebraic manipulation, the mean and variance of (6) are respectively given by

$$
E\left(D_{t}\right)=\mu_{D}=\mu_{W}
$$

and

$$
\operatorname{Var}\left(D_{t}\right)=\sigma_{D_{t}}^{2}=\frac{\lambda\left(1+\lambda^{\prime 2}-\lambda^{\prime 2 t}\left[(t+1)^{2}-\left(2 t^{2}-2 t-1\right) \lambda^{\prime 2}+t^{2} \lambda^{\prime 4}\right]\right)}{\left(1+\lambda^{\prime}\right)^{3}} \sigma_{W}^{2}
$$

with $\lambda^{\prime}=1-\lambda$. Hence, the upper and lower control limits of the DEWMA $W$ chart are computed as follows:

$$
U C L_{t} / L C L_{t}=\mu_{D} \pm L_{D} \sigma_{D_{t}}
$$

where $L_{D}>0$ is the control limits coefficient which has to be calculated such that the attained $A R L_{0}$ is close or equal to the pre-specified nominal $A R L_{0}$. Thus, the DEWMA W chart produces an OOC signal when $D_{t}$ value plots beyond the control limits in (8).

\section{The design of the TEWMA $W$ chart with and without FIR features}

\subsection{TEWMA $W$ chart without FIR features}

The TEWMA design entails applying the smoothing procedure three times; instead of twice as for the DEWMA or once as for the EWMA. Following on similar line of argument as Alevizakos et $\mathrm{al}^{36}$, it follows that the charting statistic of the TEWMA $W$ chart is given by

$$
T_{t}=\lambda D_{t}+(1-\lambda) T_{t-1},
$$

where $D_{t}$ is given in (6) and $T_{0}=\mu_{W}$. From (3), (6) and (9):

$$
\begin{aligned}
E_{t} & =\lambda W_{t}+(1-\lambda) E_{t-1} \\
D_{t} & =\lambda E_{t}+(1-\lambda) D_{t-1} \\
T_{t} & =\lambda D_{t}+(1-\lambda) T_{t-1},
\end{aligned}
$$

that is, the original $W_{t}$ statistic in (1) goes through a smoothing procedure three times; hence, simplifying each expression in (10) leads to the following: 


$$
\begin{aligned}
& E_{t}=\lambda \sum_{i=1}^{t}(1-\lambda)^{t-i} W_{i}+(1-\lambda)^{t} E_{0} \\
& D_{t}=\lambda \sum_{i=1}^{t}(1-\lambda)^{t-i} E_{i}+(1-\lambda)^{t} D_{0} \\
& T_{t}=\lambda \sum_{i=1}^{t}(1-\lambda)^{t-i} D_{i}+(1-\lambda)^{t} T_{0} .
\end{aligned}
$$

Substituting $E_{t}$ into $D_{t}$, and thereafter substituting $D_{t}$ into $T_{t}$, then after some algebraic manipulations, the charting statistic of the TEWMA $W$ chart can also be re-written as

$$
T_{t}=\frac{\lambda^{3}}{2} \sum_{j=1}^{t}(1-\lambda)^{t-j}(t-j+1)(t-j+2) W_{j}+\left(\frac{(1-\lambda)^{t}}{2}\right)(\lambda t(\lambda t+\lambda+2)+2) T_{0} .
$$

For a more detailed algebraic derivation in the case of the parametric TEWMA $\bar{X}$ chart, readers are advised to consult Alevizakos et $\mathrm{al}^{36}$. Hence, the mean and variance of (9) or (12) are respectively given by

$$
E\left(T_{t}\right)=\mu_{T}=\mu_{W}
$$

and

$$
\operatorname{Var}\left(T_{t}\right)=\sigma_{T_{t}}^{2}=\left(\frac{\lambda^{6}}{4} \sum_{j=1}^{t}(t-j+1)^{2}(t-j+2)^{2}(1-\lambda)^{2(t-j)}\right) \sigma_{W}^{2} .
$$

The simplified version of the $\operatorname{Var}\left(T_{t}\right)$ is given in the Appendix. The upper and lower control limits are respectively given by

$$
U C L_{t} / L C L_{t}=\mu_{T} \pm L_{T} \sigma_{T_{t}}
$$

where $L_{T}>0$ is the control limits coefficient which has to be calculated such that the attained $A R L_{0}$ is close or equal to the pre-specified nominal $A R L_{0}$. Thus, the TEWMA $W$ chart gives an OOC signal when $T_{t}$ value plots beyond the control limits in (14).

\subsection{TEWMA $W$ chart with a basic FIR feature}

To improve the sensitivity of the standard TEWMA $W$ chart in detecting shifts during startup, the basic FIR feature is added. This feature can be implemented to get an early alert at the beginning period of monitoring (when a change is suspected to be present) or after an OOC signal. The basic FIR feature proposed by Steiner $^{42}$ is computed as

$$
\operatorname{FIR}(t)=1-(1-f)^{(1+a)(t-1)},
$$

where it is suggested to use $f=0.5$ and $a=0.3$, with $f$ as a segment of an interval from a start-up value to the control limits. Based on the latter formulation, Steiner ${ }^{42}$ showed that the FIR feature has 'very little to none' effect in narrowing control limit of the time-varying 
control chart after the $20^{\text {th }}$ observation. Combining (14) and (15a) yields the control limits of the FIR-TEWMA $W$ chart:

$$
U C L_{t} / L C L_{t}=\mu_{T} \pm L_{T} \times \operatorname{FIR}(t) \times \sigma_{T_{t}} .
$$

At time $t$, the FIR-TEWMA $W$ chart produces an OOC signal when $T_{t}$ value plots beyond the control limits in (15b).

\subsection{TEWMA $W$ chart with a MFIR feature}

As an improvement to Steiner ${ }^{42}$, s FIR feature, Haq et $\mathrm{al}^{43}$ introduced the MFIR feature. The MFIR is computed as

$$
\operatorname{MFIR}(t)=\left(1-(1-f)^{(1+a)(t-1)}\right)^{\left(1+\frac{1}{t}\right)} .
$$

Combining (14) and (16a) yields the control limits of the MFIR-TEWMA $W$ chart:

$$
U C L_{t} / L C L_{t}=\mu_{T} \pm L_{T} \times \operatorname{MFIR}(t) \times \sigma_{T_{t}} .
$$

The MFIR-TEWMA $W$ chart produces an OOC signal at time $t$ when $T_{t}$ value plots beyond the control limits in (16b). Haq et $\mathrm{al}^{43}$ similarly showed that after the $20^{\text {th }}$ observation, the MFIR feature has a 'very little to none' effect on narrowing the control limits of the timevarying control chart.

\subsection{TEWMA $W$ chart with a IMFIR feature}

This paper also proposes a new FIR feature called the IMFIR feature where the power transformation factor is multiplied by square root of time. As it will be seen, the advantage of this new feature is that the sensitivity of the proposed TEWMA $W$ chart increases the ability to detect any shifts at start-up period of the process as soon as possible. That is, it allows time-varying control limits to be narrower at the early stages of the process to better detect start-up problems, while ensuring that the long-run properties of the time-varying monitoring scheme are not disturbed. The IMFIR feature is defined by

$$
\operatorname{IMFIR}(t)=\left(1-(1-f)^{(1+a)(t-1)}\right)^{\sqrt{t}\left(1+\frac{1}{t}\right)},
$$

where the values of $f$ and $a$ are taken as 0.5 and 0.3 , respectively. Combining (14) and (17a) yields the control limits of the IMFIR-TEWMA $W$ chart:

$$
U C L_{t} / L C L_{t}=\mu_{T} \pm L_{T} \times \operatorname{IMFIR}(t) \times \sigma_{T_{t}} .
$$

The IMFIR-TEWMA $W$ chart produces an OOC signal when $T_{t}$ value plots beyond the control limits in (17b).

In Figure 1, the adjustment factors in (15a), (16a) and (17a) are compared against each other as time increases. This is an extension of Figure 1 in Haq et $\mathrm{al}^{43}$ to illustrate how the new IMFIR feature is an improvement of both FIR and MFIR features by Steiner $^{42}$ and Haq et 
$\mathrm{al}^{43}$. The adjustment factors of FIR, MFIR and IMFIR converge to unity as time increases; based on Figure 1, it is apparent that those of FIR and MFIR does so at time point equal to 24, while that of IMFIR does so at time point equal to 32. Moreover, while the adjustment factor of MFIR is smaller than that of FIR whenever $t \leq 15$ and thereafter, they are equal; that of IMFIR is only equal to those of FIR and MFIR at sampling time 32 and onwards. This implies that the IMFIR feature reduces the control limits much further than the FIR and MFIR features at the start-up period (while not disturbing its long-run properties), and thus increase the detection capability of a time-varying TEWMA scheme.

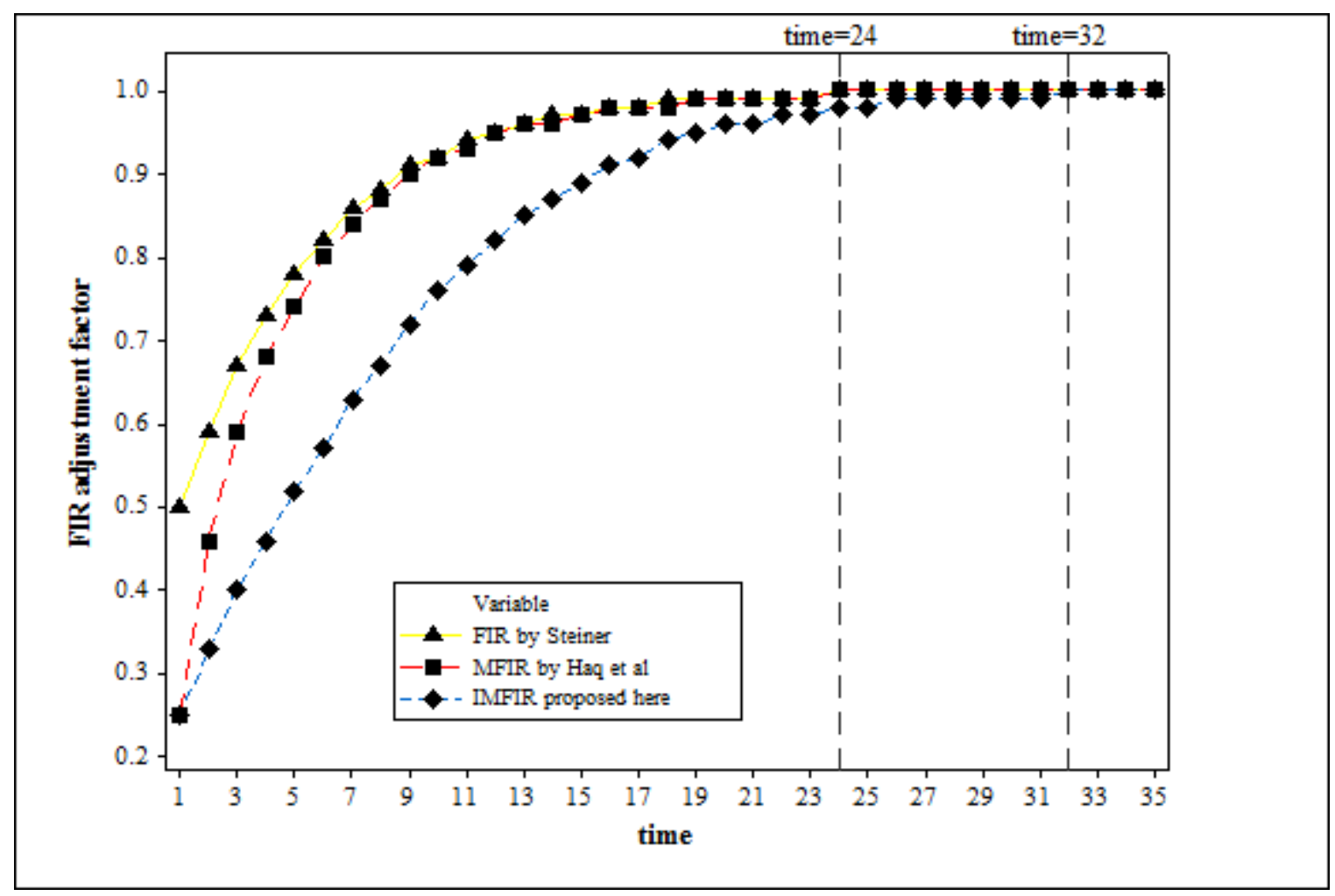

Figure 1: Comparison of the FIR, MFIR and IMFIR adjustment factors with respect to time

\subsection{The implementation of IMFIR-TEWMA $W$ charts}

The IMFIR-TEWMA $W$ chart can be implemented as follows:

Step 1: Generate a phase I sample of size $m, X$, from an IC process (e.g., from $N(0,1)$ ).

Step 2: Generate a phase II sample of size $n, Y$. When the process is IC, the distributions of the phases I and II are identical (i.e. $\delta=0$ ). Otherwise, the distribution for the phase II sample is taken to be similar to that for the phase I sample, but with a change in the mean parameter $(\delta \neq 0)$ (e.g. from $N(\delta, 1))$.

Step 3: The $W$ statistic is computed by combining the phase I and phase II samples using (1). 
Step 4: Find the mean and variance of $W$ when the process is IC using (2). These are used in Steps 5 and 6.

Step 5: Compute the plotting statistic using (9) or (12) and choose $L_{T}$ such that the attained $A R L_{0} \approx 500$. The time-varying control limits of the IMFIR-TEWMA chart are calculated using (17b).

Step 6: The IMFIR-TEWMA $W$ chart gives a signal if the plotting statistic computed is Step 5 plots beyond the control limits calculated in Step 5.

The FIR-TEWMA and MFIR-TEWMA charts can also be implemented in a similar way.

\section{Performance analysis and comparisons of the proposed control charts}

\subsection{Performance metrics}

The run-length $(R L), A R L$, standard deviation of the $R L(S D R L)$ and expected $A R L(E A R L)$ characteristics are often used to explore how sensitive is the explored control chart. The $R L$ refers to the number of charting statistics to be plotted on the chart before the first OOC signal. In this paper, Monte Carlo simulations are used with 20000 replications to assess the TEWMA schemes with and without FIR features. When the overall performance is of interest, the $E A R L$ metric is recommended. The $E A R L$ is mathematically defined by

$$
E A R L_{\left(\delta_{\min }, \delta_{\max }\right]}=\frac{1}{\Delta} \sum_{\delta=\delta_{\min }}^{\delta_{\max }} A R L(\delta)
$$

where $\Delta$ is the number of increments between the $\delta_{\min }$ (lower limit of $\delta$ ) and $\delta_{\max }$ (upper limit of $\delta)$.

\subsection{IC robustness}

To study the robustness of the proposed charts, three distributions are considered, i.e., the standard normal (denoted as $N(0,1)$ ), Student's $t(v)$ (with $v=5,15$ and 30), Gamma $(\beta, 1)$ (denoted by $\operatorname{GAM}(\beta, 1)$ with $\beta=1,3$ and 15) distributions are used. A control chart is considered to be IC robust when the characteristics of the IC $R L$ are approximately the same across all continuous probability distributions (see for instance Chakraborti and Graham ${ }^{1}$ ). Table 1 shows the robustness of the TEWMA $W$ charts with and without FIR features when $(m, n)=(100,5)$ and $\lambda \in\{0.05,0.5\}$ for a nominal $A R L_{0}=500$. From Table 1 , it can be noticed that, the attained IC $A R L_{0}$ values are close to each other across different distributions and similarly, the attained IC $S D R L_{0}$ are also close to each other across different distributions. For instance, the attained IC $A R L_{0}$ are around 500 for all the distributions considered in this paper. In addition, it is observed that the TEWMA $W$ chart with no FIR 
feature has lower $S D R L_{0}$ values than the ones with FIR features. Note that $5^{\text {th }}, 25^{\text {th }}, 50^{\text {th }}, 75^{\text {th }}$ and $95^{\text {th }}$ percentiles are denoted as P5, P25, P50, P75 and P95, respectively and are presented in Figure 1. Moreover, it is shown in Figure 2 that the $A R L_{0}, \mathrm{P} 5, \mathrm{P} 25, \mathrm{P} 50$ and $\mathrm{P} 75$ of the $R L$ distribution are almost constant, while the ones of the $S D R L_{0}$ and P95 have a slight (but insignificant) variation. Thus, based on Table 1 and Figure 2, it can be deduced that the TEWMA $W$ chart with or without FIR features is IC robust. It is important to mention that the SDRL and P95 profiles of the TEWMA $W$ with the IMFIR feature are larger than the one with no FIR feature, see Figures 2(a) and (b); a high IC SDRL is undesired as it may lead to a high probability of an OOC signal, when in fact the process is IC.

Table 1. Robustness of the TEWMA $W$ with and without FIR feature when $(m, n)=(100,5)$, $\lambda \in\{0.05,0.5\}$ for a nominal $A R L_{0}=500$ under different distributions

\begin{tabular}{|c|c|c|c|c|c|c|c|c|c|}
\hline & & TE & VMA & FIR-' & WMA & MFIR & EWMA & IMFIR & EWMA \\
\hline$\lambda$ & Distribution & $A R L_{0}$ & $S D R L_{0}$ & $A R L_{0}$ & $S D R L_{0}$ & $A R L_{0}$ & $S D R L_{0}$ & $A R L_{0}$ & $S D R L_{0}$ \\
\hline \multirow{8}{*}{0.05} & $N(0,1)$ & 500.3 & 961.3 & 502.9 & 1166.7 & 500.8 & 1697.0 & 499.3 & 1506.6 \\
\hline & $t(5)$ & 496.2 & 939.3 & 502.0 & 1128.6 & 514.0 & 1611.0 & 497.3 & 1580.4 \\
\hline & $t(15)$ & 508.2 & 961.6 & 506.5 & 1163.4 & 501.3 & 1670.9 & 495.5 & 1480.5 \\
\hline & $t(30)$ & 496.5 & 941.2 & 507.7 & 1173.2 & 519.3 & 1660.0 & 504.0 & 1807.9 \\
\hline & $G A M(1,1)$ & 501.4 & 956.3 & 503.8 & 1138.0 & 489.5 & 1616.6 & 499.1 & 1638.8 \\
\hline & $\operatorname{GAM}(3,1)$ & 500.4 & 945.8 & 500.4 & 1142.6 & 517.0 & 1657.3 & 505.4 & 1710.0 \\
\hline & $\operatorname{GAM}(15,1)$ & 510.1 & 950.8 & 502.8 & 1125.5 & 502.1 & 1563.4 & 500.7 & 1619.7 \\
\hline & $L_{T}$ & \multicolumn{2}{|c|}{2.321} & \multicolumn{2}{|c|}{2.424} & \multicolumn{2}{|c|}{2.624} & \multicolumn{2}{|c|}{2.617} \\
\hline \multirow{8}{*}{0.5} & $N(0,1)$ & 500.2 & 725.0 & 498.5 & 870.7 & 506.2 & 1228.2 & 494.4 & 1592.5 \\
\hline & $t(5)$ & 507.1 & 735.6 & 508.2 & 879.6 & 498.7 & 1152.5 & 511.0 & 1631.2 \\
\hline & $t(15)$ & 507.1 & 778.6 & 496.0 & 867.5 & 503.0 & 1240.2 & 511.2 & 1635.5 \\
\hline & $t(30)$ & 501.6 & 739.4 & 508.2 & 882.4 & 500.5 & 1171.9 & 505.5 & 1591.6 \\
\hline & $\operatorname{GAM}(1,1)$ & 495.7 & 702.9 & 505.9 & 884.7 & 507.6 & 1192.5 & 509.4 & 1626.7 \\
\hline & $\operatorname{GAM}(3,1)$ & 495.5 & 705.6 & 496.4 & 896.6 & 502.0 & 1181.0 & 508.7 & 1623.8 \\
\hline & $\operatorname{GAM}(15,1)$ & 511.6 & 729.0 & 501.0 & 871.2 & 508.9 & 1229.2 & 498.5 & 1529.5 \\
\hline & $L_{T}$ & \multicolumn{2}{|c|}{2.933} & \multicolumn{2}{|c|}{2.995} & \multicolumn{2}{|c|}{3.126} & \multicolumn{2}{|c|}{3.210} \\
\hline
\end{tabular}

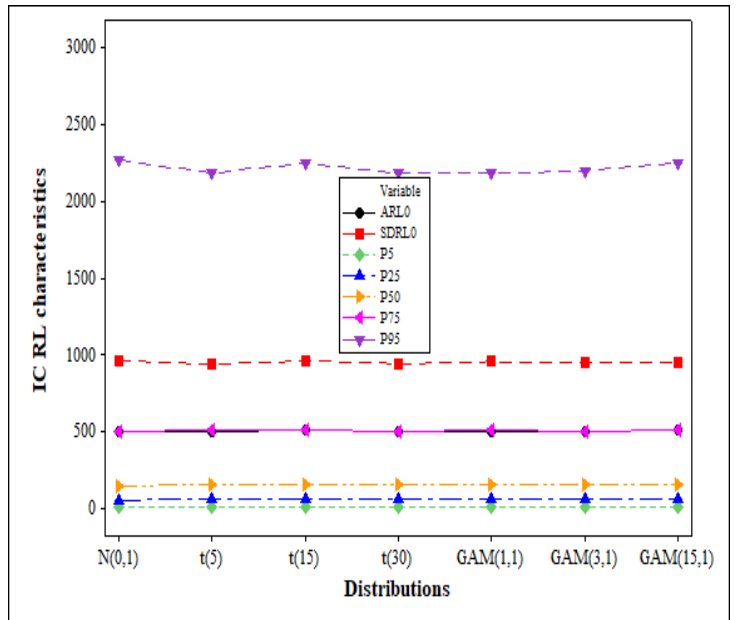

(a) TEWMA $W$ chart (with no FIR feature)

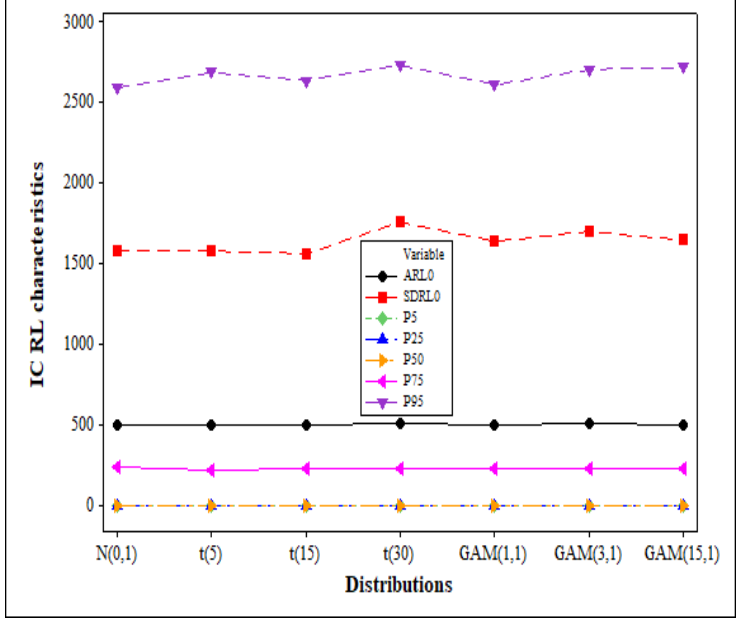

(b) IMFIR-TEWMA $W$ chart

Figure 2. Robustness of the proposed charts when $(m, n)=(100,5), \lambda=0.05$ for a nominal $A R L_{0}=500$ under different distributions 


\subsection{OOC performance}

Table 2 shows that the OOC ARL of the TEWMA $W$ chart are lower for small values of $\lambda$, but increase as $\lambda$ increases, indicating a deteriorating performance. For small and moderate shifts in the process location, the proposed chart performs better under the heavy-tailed $t$ distribution followed by the normal distribution. However, for large shifts, their performances under the different distributions are almost similar. For skewed gamma distribution, the higher the value of $\lambda$, the worse the performance; for instance, when $\delta=0.1, \lambda=0.9$, under the $\operatorname{GAM}(3,1)$ distribution, the OOC $A R L$ is equal to 534.8 (i.e. higher than the nominal $A R L_{0}$ value of 500, which implies that it is $A R L$-biased). Next, the $E A R L$ values increase as $\lambda$ increases for each distribution in Table 2, indicating a deteriorating OOC performance. For instance, under the $N(0,1)$ distribution, when $\lambda=0.05,0.5$ and 0.9 , then the corresponding $E A R L$ values are equal to 38.3, 45.4 and 61.7, respectively. In addition, Figure 3 studies the effect of Phase II sample size, i.e. $n \in\{3,5,10\}$, on the OOC performance using the EARLs when $\lambda \in\{0.05,0.5\}$. Figure 3 shows that as the Phase II sample size increases, the better the Phase II OOC performance becomes, thus indicating an improvement in the detection ability. Similarly, Figure 4 shows that the larger the Phase I sample size $(m)$, the better the Phase II OOC performance. Figures 3 and 4 show that the larger the smoothing parameter, the less sensitive is the TEWMA $W$ chart, since the EARLs become larger; especially for the skewed gamma distribution.

Table 2. The $A R L$ profile of the TEWMA $W$ chart when $(m, n)=(100,5), \lambda \in\{0.05,0.5$, $0.9\}, \delta_{\min }=0$ and $\delta_{\max }=1.5$ with an increment of 0.1 for a nominal $A R L_{0}=500$ under different distributions

\begin{tabular}{|c|ccc|cccc|ccc|}
\cline { 2 - 10 } \multicolumn{1}{c|}{} & \multicolumn{3}{c|}{$\boldsymbol{N}(\mathbf{0 , 1})$} & \multicolumn{3}{c|}{$\boldsymbol{t}(\mathbf{5})$} & \multicolumn{3}{c|}{$\boldsymbol{G A M ( 3 , 1 )}$} \\
\hline Shift & $\boldsymbol{\lambda}=\mathbf{0 . 0 5}$ & $\boldsymbol{\lambda}=\mathbf{0 . 5}$ & $\boldsymbol{\lambda}=\mathbf{0 . 9}$ & $\boldsymbol{\lambda}=\mathbf{0 . 0 5}$ & $\boldsymbol{\lambda}=\mathbf{0 . 5}$ & $\boldsymbol{\lambda}=\mathbf{0 . 9}$ & $\boldsymbol{\lambda}=\mathbf{0 . 0 5}$ & $\boldsymbol{\lambda}=\mathbf{0 . 5}$ & $\boldsymbol{\lambda}=\mathbf{0 . 9}$ \\
\cline { 2 - 10 } & 355.3 & 369.1 & 408.3 & 304.5 & 360.0 & 401.9 & 339.9 & 435.2 & 534.8 \\
0.1 & 126.5 & 176.5 & 244.4 & 93.3 & 137.6 & 224.7 & 110.1 & 192.1 & 357.9 \\
0.3 & 36.7 & 63.6 & 121.9 & 24.1 & 39.9 & 103.9 & 28.9 & 63.9 & 184.6 \\
0.4 & 16.4 & 24.6 & 61.0 & 11.8 & 16.3 & 46.4 & 13.2 & 21.5 & 82.2 \\
0.5 & 9.7 & 12.2 & 32.8 & 7.5 & 8.9 & 23.4 & 7.6 & 10.3 & 42.1 \\
0.6 & 6.7 & 7.8 & 17.7 & 5.3 & 5.9 & 12.7 & 5.3 & 6.3 & 23.1 \\
0.7 & 4.9 & 5.4 & 10.9 & 3.9 & 4.5 & 7.8 & 3.9 & 4.6 & 12.4 \\
0.8 & 3.8 & 4.3 & 7.3 & 3.1 & 3.5 & 5.3 & 3.0 & 3.6 & 7.9 \\
0.9 & 3.1 & 3.5 & 5.3 & 2.5 & 2.9 & 3.8 & 2.4 & 3.0 & 5.4 \\
1.0 & 2.5 & 3.0 & 4.0 & 2.1 & 2.5 & 3.0 & 2.0 & 2.6 & 3.9 \\
1.1 & 2.1 & 2.6 & 3.2 & 1.8 & 2.3 & 2.5 & 1.7 & 2.3 & 2.9 \\
1.2 & 1.9 & 2.3 & 2.6 & 1.6 & 2.0 & 2.2 & 1.5 & 2.1 & 2.4 \\
1.3 & 1.6 & 2.1 & 2.3 & 1.4 & 1.8 & 1.8 & 1.4 & 1.9 & 2.1 \\
1.4 & 1.5 & 1.9 & 2.0 & 1.3 & 1.7 & 1.7 & 1.2 & 1.8 & 1.8 \\
1.5 & 1.3 & 1.7 & 1.8 & 1.2 & 1.5 & 1.5 & 1.1 & 1.6 & 1.6 \\
\hline$E A R L_{(0,1.5]}$ & 38.3 & 45.4 & 61.7 & 31.0 & 39.4 & 56.2 & 34.9 & 50.2 & 84.3 \\
$L_{T}$ & 2.321 & 2.933 & 2.851 & 2.321 & 2.933 & 2.851 & 2.321 & 2.933 & 2.851 \\
\hline
\end{tabular}




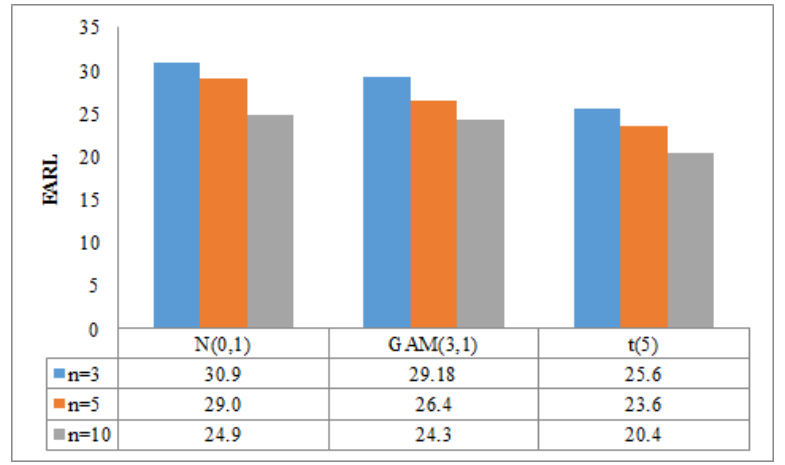

(a) $\lambda=0.05$

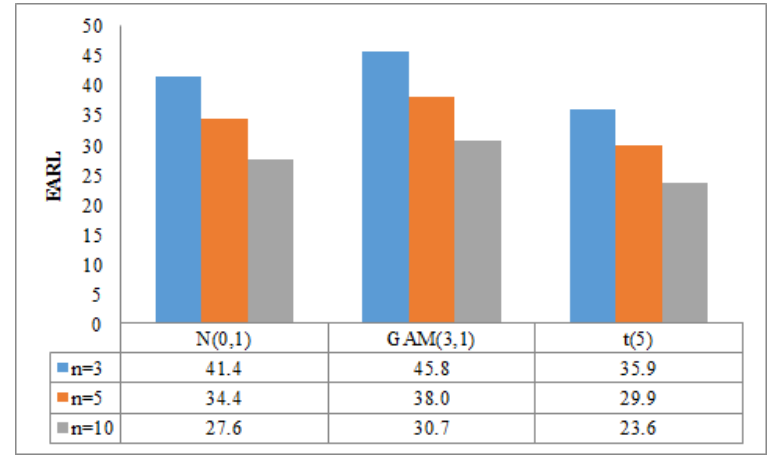

(b) $\lambda=0.5$

Figure 3. The effect of Phase II sample size on the performance TEWMA $W$ chart using the $E A R L$ when $m=100, n \in\{3,5,10\}, \lambda \in\{0.05,0.5\}, \delta_{\min }=0$ and $\delta_{\max }=2$ with an increment of 0.1

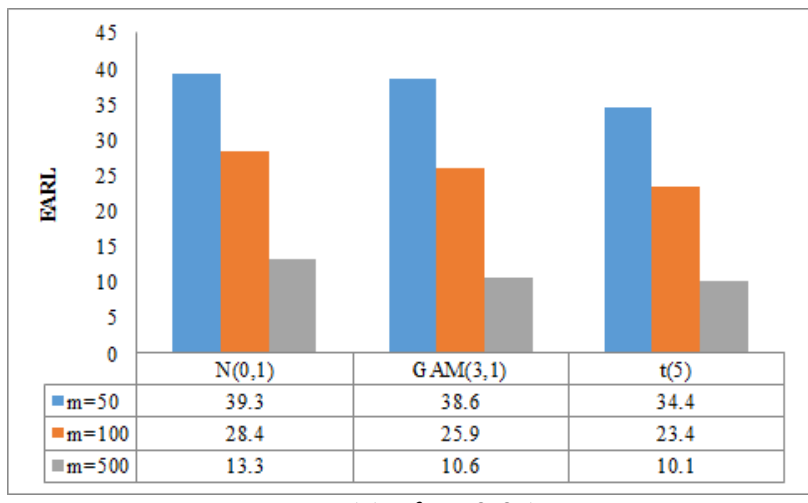

(a) $\lambda=0.05$

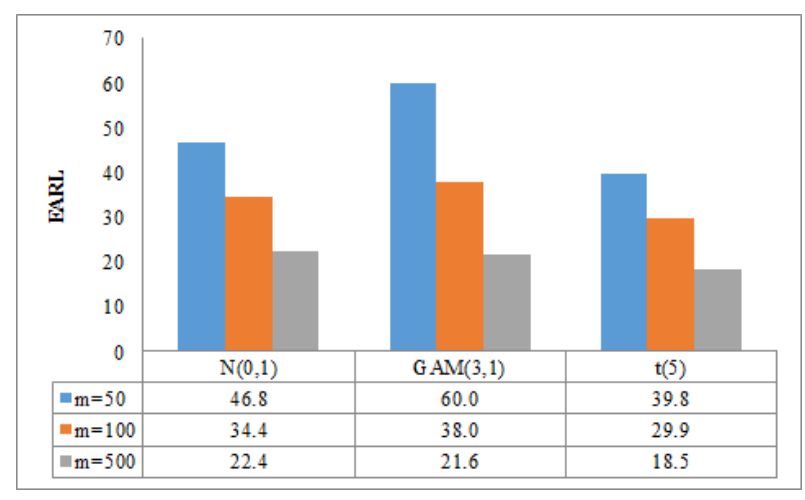

(b) $\lambda=0.5$

Figure 4. The effect of Phase I sample size on the performance TEWMA $W$ chart using the $E A R L$ when $m=100, m \in\{50,100,500\}, \lambda \in\{0.05,0.5\}, \delta_{\min }=0$ and $\delta_{\max }=2$ with an increment of 0.1

At each shift value and for different EARLs, the best performing chart is boldfaced in Tables 4 to 6. Note that $E A R L_{(0,0.5]}, E A R L_{(1,1.5]}$ and $E A R L_{(0,1.5]}$ denote overall performance metrics defined in (18) for 'small', 'large' and 'small-to-large' shifts, respectively. Based on the OOC $A R L$ performance illustrated in Table 3, it shows that the IMFIR-TEWMA $W$ chart is more sensitive than the standard TEWMA, FIR-TEWMA and MFIR-TEWMA $W$ charts for all shift values as well as in terms of the EARL values under symmetric distributions. However, for small shifts under skewed distributions, the IMFIR-TEWMA $W$ chart is outperformed by its competitors, see Table 3 when $\delta=0.1$ under the $\operatorname{GAM}(3,1)$ distribution. For symmetric distributions, the IMFIR-TEWMA $W$ chart has a better overall performance than the other charts, see the EARL values under the $N(0,1)$ and $t(5)$ distributions. However, for the skewed gamma distribution, the FIR-TEWMA $W$ chart is slightly better than the other charts. It is important to note that, in Table 3, the TEWMA $W$ chart with no FIR feature has the worst performance than those with FIR, MFIR or IMFIR. 
Table 3. The $A R L$ profile of the TEWMA $W$ with and without FIR features when $(m, n, \lambda)=$ $(100,5,0.5)$ for a nominal $A R L_{0}=500$ under different distributions

\begin{tabular}{|c|c|c|c|c|c|c|c|c|c|c|c|c|}
\hline \multirow[b]{2}{*}{ Shift } & \multicolumn{4}{|c|}{$N(0,1)$} & \multicolumn{4}{|c|}{$t(5)$} & \multicolumn{4}{|c|}{$\operatorname{GAM}(3,1)$} \\
\hline & TEWMA & $\begin{array}{c}\text { FIR- } \\
\text { TEWMA }\end{array}$ & $\begin{array}{c}\text { MFIR- } \\
\text { TEWMA }\end{array}$ & $\begin{array}{c}\text { IMFIR- } \\
\text { TEWMA }\end{array}$ & TEWMA & $\begin{array}{c}\text { FIR- } \\
\text { TEWMA }\end{array}$ & $\begin{array}{c}\text { MFIR- } \\
\text { TEWMA }\end{array}$ & $\begin{array}{c}\text { IMFIR- } \\
\text { TEWMA }\end{array}$ & TEWMA & $\begin{array}{c}\text { FIR- } \\
\text { TEWMA }\end{array}$ & $\begin{array}{c}\text { MFIR- } \\
\text { TEWMA }\end{array}$ & $\begin{array}{c}\text { IMFIR- } \\
\text { TEWMA }\end{array}$ \\
\hline 0.1 & 369.1 & 371.8 & 373.9 & 357.5 & 360.0 & 351.5 & 340.6 & 328.2 & 435.2 & 428.9 & 452.9 & 478.5 \\
\hline 0.2 & 176.5 & 170.1 & 157.8 & 142.0 & 137.7 & 127.2 & 119.2 & 98.6 & 192.1 & 203.5 & 197.8 & 187.1 \\
\hline 0.3 & 63.6 & 51.7 & 47.2 & 35.7 & 40.0 & 30.5 & 28.2 & 18.0 & 63.9 & 59.0 & 56.6 & 39.4 \\
\hline 0.4 & 24.6 & 15.6 & 13.8 & 9.5 & 16.3 & 9.7 & 7.2 & 4.6 & 21.5 & 14.2 & 11.9 & 14.2 \\
\hline 0.5 & 12.2 & 6.6 & 4.9 & 3.0 & 9.0 & 4.7 & 3.0 & 2.1 & 10.3 & 5.6 & 3.8 & 2.3 \\
\hline 0.6 & 7.8 & 4.0 & 2.7 & 1.9 & 5.9 & 2.8 & 1.9 & 1.6 & 6.3 & 3.0 & 2.1 & 1.6 \\
\hline 0.7 & 5.4 & 2.7 & 1.9 & 1.5 & 4.5 & 2.1 & 1.5 & 1.3 & 4.6 & 2.1 & 1.5 & 1.3 \\
\hline 0.8 & 4.3 & 2.0 & 1.5 & 1.3 & 3.5 & 1.7 & 1.3 & 1.2 & 3.6 & 1.6 & 1.2 & 1.1 \\
\hline 0.9 & 3.5 & 1.7 & 1.3 & 1.2 & 3.0 & 1.4 & 1.2 & 1.1 & 3.0 & 1.3 & 1.1 & 1.1 \\
\hline 1.0 & 3.0 & 1.4 & 1.2 & 1.1 & 2.5 & 1.3 & 1.1 & 1.1 & 2.6 & 1.2 & 1.0 & 1.0 \\
\hline 1.1 & 2.6 & 1.3 & 1.1 & 1.1 & 2.3 & 1.2 & 1.1 & 1.1 & 2.3 & 1.1 & 1.0 & 1.0 \\
\hline 1.2 & 2.3 & 1.2 & 1.1 & 1.0 & 2.0 & 1.1 & 1.0 & 1.0 & 2.1 & 1.1 & 1.0 & 1.0 \\
\hline 1.3 & 2.1 & 1.1 & 1.0 & 1.0 & 1.8 & 1.1 & 1.0 & 1.0 & 1.9 & 1.0 & 1.0 & 1.0 \\
\hline 1.4 & 1.9 & 1.1 & 1.0 & 1.0 & 1.7 & 1.1 & 1.0 & 1.0 & 1.8 & 1.0 & 1.0 & 1.0 \\
\hline 1.5 & 1.7 & 1.1 & 1.0 & 1.0 & 1.6 & 1.0 & 1.0 & 1.0 & 1.6 & 1.0 & 1.0 & 1.0 \\
\hline$E A R L_{(0,0.5]}$ & 129.2 & 123.2 & 119.5 & 109.5 & 112.6 & 104.7 & 99.6 & 90.3 & 144.6 & 142.2 & 144.6 & 144.3 \\
\hline$E A R L_{(1,1.5]}$ & 2.1 & 1.2 & 1.0 & 1.0 & 1.9 & 1.1 & 1.0 & 1.0 & 1.9 & 1.0 & 1.0 & 1.0 \\
\hline$E A R L_{(0,1.5]}$ & 45.4 & 42.2 & 40.8 & 37.3 & 39.5 & 35.9 & 34.0 & 30.9 & 50.2 & 48.4 & 49.0 & 48.8 \\
\hline$L_{T}$ & 2.933 & 2.995 & 3.126 & 3.2095 & 2.933 & 2.995 & 3.126 & 3.2095 & 2.933 & 2.995 & 3.126 & 3.2095 \\
\hline
\end{tabular}

Since the $A R L$ values are spread over a wide range of values; hence, in Figure 5, they are displayed in a compact manner using the $\log$ scale, i.e. $\log _{10}(A R L)$. From Figure 5 , it is observed that, in general, the standard TEWMA $W$ chart will take longer to give a signal as compared to the FIR-TEWMA, MFIR-TEWMA and IMFIR-TEWMA $W$ charts for the majority of shifts. However, for most shifts, the IMFIR-TEWMA $W$ chart detects changes in the location parameter faster, with the MFIR-TEWMA and FIR-TEWMA $W$ charts, being the second and third best for the majority of shifts, respectively.

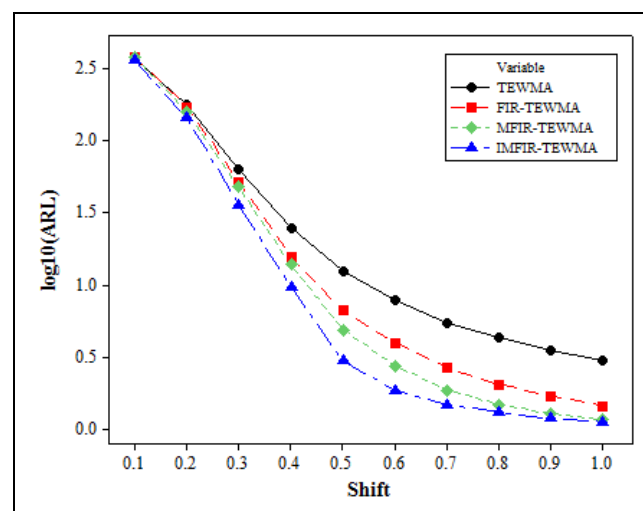

(a) $N(0,1)$ distribution

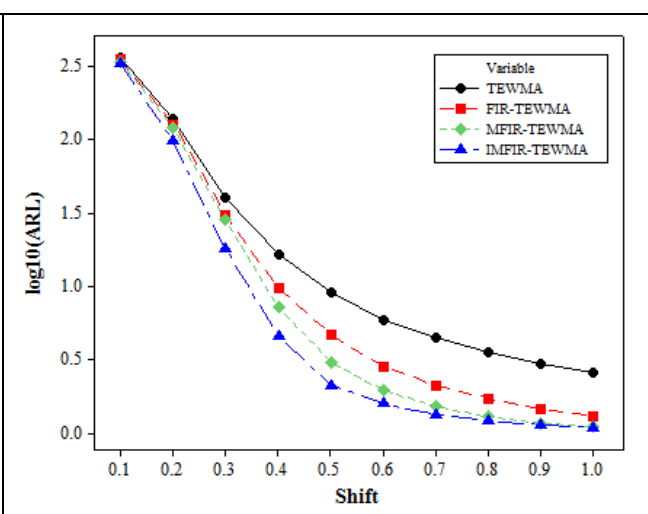

(b) $t(5)$ distribution

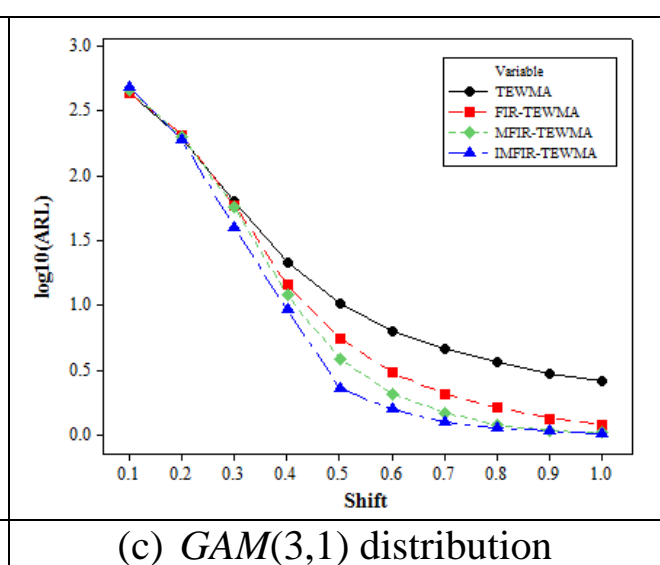

(c) $\operatorname{GAM}(3,1)$ distribution

Figure 5. The OOC $\log _{10}(A R L)$ profile comparison of the proposed schemes when $(m, n)=$ $(100,5), \lambda=0.05$ for a nominal $A R L_{0}=500$ under different distributions

\subsection{Performance comparison of the EWMA, DEWMA and TEWMA $W$ charts}

In Tables 4 to 6 , the proposed TEWMA $W$ chart is compared to the EWMA and DEWMA $W$ charts with and without FIR features when $\lambda=0.5, m=100$ and $n=5$ under the $N(0,1), t(5)$ 
and $\operatorname{GAM}(3,1)$, respectively. It is worth mentioning that the EWMA and DEWMA $W$ charts discussed in $\mathrm{Li}$ et $\mathrm{al}^{26}$ and Malela-Majika ${ }^{28}$ did not incorporate any of the FIR features discussed here. For control charts with no FIRs (i.e. labelled 'Standard' in Tables 4 to 6), the TEWMA $W$ chart has the best small as well as large shifts performance; however, the DEWMA $W$ chart has better moderate shifts performance. With respect to EARLs, the TEWMA $W$ chart has the best performance followed by the DEWMA $W$ chart and finally, the EWMA $W$ chart being the worst performing.

Next, for control charts with FIR and MFIR features, the DEWMA and TEWMA $W$ charts seem to have the best small shifts performance, with the TEWMA chart having a slight advantage based on the $E A R L_{(0,0.5]}$ values. Note though, for moderate shifts, the DEWMA $W$ chart has better performance. For large shifts, i.e. for $\delta \geq 1$, the competing charts are almost equivalent, see the $E A R L_{(1,1.5]}$ values in Tables 4 to 6.

Finally, for control charts with IMFIR feature, the TEWMA $W$ chart seems to have the best small shifts performance, see the $E A R L_{(0,0.5]}$ values in Tables 4 to 6; with the DEWMA $W$ chart having the second best performance. Again, for moderate shifts, the DEWMA $W$ chart has a better performance. For large shifts, all the competing charts are almost equivalent; see the $E A R L_{(1,1.5]}$ values in Tables 4 to 6 .

In general, from Tables 4 to 6 , it is observed that in most situations (with or without the FIR features), the TEWMA $W$ chart has relatively better OOC performance for small and large shifts; however, the DEWMA $W$ chart has excellent moderate shifts detection ability than its competitors. Moreover, comparing the EWMA, DEWMA and TEWMA $W$ charts' $A R L$ and $E A R L$ values from the columns, 'Standard' vs. 'FIR' vs. 'MFIR' vs. 'IMFIR': the feature that results in the lowest $A R L$ and $E A R L$ values, correspond to the IMFIR. The latter shows that for each chart, the IMFIR feature yields the best performance in most situations. 
Table 4. The OOC $A R L$ profile comparison of the EWMA, DEWMA and TEWMA charts with and without FIR features when $(m, n, \lambda)=(100,5,0.5)$ for a nominal $A R L_{0}=500$ under the $N(0,1)$ distribution

\begin{tabular}{|c|c|c|c|c|c|c|c|c|c|c|c|c|}
\hline & \multicolumn{3}{|c|}{ Standard } & \multicolumn{3}{|c|}{ FIR } & \multicolumn{3}{|c|}{ MFIR } & \multicolumn{3}{|c|}{ IMFIR } \\
\hline Shift & EWMA & DEWMA & TEWMA & EWMA & $\overline{\text { DEWMA }}$ & TEWMA & EWMA & $\overline{\text { DEWMA }}$ & TEWMA & EWMA & $\overline{\text { DEWMA }}$ & TEWMA \\
\hline 0.1 & 357.7 & 354.3 & 352.7 & 353.2 & 335.8 & 349.1 & 340.4 & 327.5 & 340.8 & 340.2 & 326.1 & 333.6 \\
\hline 0.2 & 142.5 & 128.5 & 118.0 & 132.3 & 117.6 & 120.6 & 116.6 & 116.5 & 108.2 & 117.7 & 110.9 & 99.2 \\
\hline 0.3 & 38.9 & 36.6 & 37.5 & 32.9 & 33.1 & 32.6 & 26.4 & 25.9 & 25.1 & 27.0 & 26.6 & 23.7 \\
\hline 0.4 & 15.6 & 14.2 & 15.6 & 12.7 & 11.7 & 13.0 & 9.2 & 9.0 & 9.1 & 9.1 & 8.1 & 9.3 \\
\hline 0.5 & 9.3 & 8.8 & 9.8 & 7.3 & 7.0 & 7.8 & 5.1 & 4.2 & 5.4 & 5.2 & 5.1 & 5.4 \\
\hline 0.6 & 6.5 & 6.1 & 6.7 & 5.0 & 4.7 & 5.2 & 3.3 & 2.8 & 3.8 & 3.4 & 3.3 & 3.6 \\
\hline 0.7 & 5.0 & 4.7 & 5.1 & 3.5 & 3.4 & 3.7 & 2.4 & 2.0 & 2.7 & 2.5 & 2.4 & 2.6 \\
\hline 0.8 & 4.0 & 3.6 & 3.8 & 2.7 & 2.6 & 2.7 & 1.8 & 1.5 & 2.0 & 1.9 & 1.9 & 2.0 \\
\hline 0.9 & 3.3 & 3.0 & 3.0 & 2.2 & 2.0 & 2.1 & 1.5 & 1.3 & 1.6 & 1.5 & 1.5 & 1.5 \\
\hline 1.0 & 2.9 & 2.5 & 2.5 & 1.8 & 1.7 & 1.7 & 1.3 & 1.2 & 1.4 & 1.3 & 1.3 & 1.3 \\
\hline 1.1 & 2.5 & 2.1 & 2.1 & 1.5 & 1.5 & 1.4 & 1.2 & 1.2 & 1.2 & 1.2 & 1.2 & 1.2 \\
\hline 1.2 & 2.2 & 1.9 & 1.9 & 1.3 & 1.3 & 1.2 & 1.1 & 1.1 & 1.1 & 1.1 & 1.1 & 1.1 \\
\hline 1.3 & 2.0 & 1.7 & 1.6 & 1.2 & 1.2 & 1.2 & 1.1 & 1.0 & 1.1 & 1.1 & 1.1 & 1.1 \\
\hline 1.4 & 1.9 & 1.5 & 1.5 & 1.1 & 1.1 & 1.1 & 1.0 & 1.0 & 1.0 & 1.0 & 1.0 & 1.0 \\
\hline 1.5 & 1.7 & 1.4 & 1.3 & 1.1 & 1.1 & 1.1 & 1.0 & 1.0 & 1.0 & 1.0 & 1.0 & 1.0 \\
\hline $\operatorname{EARL}_{(0,0.5]}$ & 112.8 & 108.5 & 106.7 & 107.7 & 101.0 & 104.6 & 99.5 & 96.6 & 97.7 & 99.8 & 95.4 & 94.2 \\
\hline$E A R L_{(1,1.5]}$ & 2.1 & 1.7 & 1.7 & 1.3 & 1.2 & 1.2 & 1.1 & 1.1 & 1.1 & 1.1 & 1.1 & 1.1 \\
\hline $\operatorname{EARL}_{(0,1.5]}$ & 39.7 & 38.1 & 37.5 & 37.3 & 35.0 & 36.3 & 34.2 & 33.1 & 33.7 & 34.3 & 32.8 & 32.5 \\
\hline$L_{T}$ & 2.906 & 2.474 & 2.318 & 2.991 & 2.575 & 2.423 & 3.135 & 2758 & 2.624 & 3.12 & 2.75 & 2.623 \\
\hline
\end{tabular}

Table 5. The OOC ARL profile comparison of the EWMA, DEWMA and TEWMA charts with and without FIR features when $(m, n, \lambda)=(100,5,0.5)$ for a nominal $A R L_{0}=500$ under the $t(5)$ distribution

\begin{tabular}{|c|c|c|c|c|c|c|c|c|c|c|c|c|}
\hline & \multicolumn{3}{|c|}{ Standard } & \multicolumn{3}{|c|}{ FIR } & \multicolumn{3}{|c|}{ MFIR } & \multicolumn{3}{|c|}{ IMFIR } \\
\hline Shift & EWMA & DEWMA & TEWMA & EWMA & DEWMA & TEWMA & EWMA & DEWMA & TEWMA & EWMA & DEWMA & TEWMA \\
\hline 0.1 & 337.5 & 318.7 & 306.3 & 322.3 & 316.1 & 308.7 & 320.1 & 300.1 & 315.3 & 324.5 & 293.8 & 277.4 \\
\hline 0.2 & 97.1 & 87.5 & 88.0 & 93.0 & 77.9 & 77.8 & 88.8 & 75.5 & 75.3 & 86.1 & 74.7 & 81.8 \\
\hline 0.3 & 26.5 & 22.2 & 25.1 & 21.4 & 21.5 & 23.3 & 15.2 & 16.4 & 13.9 & 17.2 & 15.6 & 15.9 \\
\hline 0.4 & 11.3 & 10.6 & 12.1 & 9.6 & 8.7 & 10.4 & 6.4 & 6.1 & 6.7 & 6.2 & 6.1 & 6.7 \\
\hline 0.5 & 7.3 & 6.7 & 7.5 & 5.8 & 5.4 & 6.0 & 3.8 & 3.7 & 4.2 & 3.9 & 3.7 & 4.1 \\
\hline 0.6 & 5.3 & 4.8 & 5.3 & 3.8 & 3.7 & 4.0 & 2.6 & 2.6 & 2.9 & 2.6 & 2.5 & 2.8 \\
\hline 0.7 & 4.1 & 3.7 & 4.0 & 2.8 & 2.7 & 2.8 & 2.0 & 1.9 & 2.1 & 1.9 & 1.9 & 2.0 \\
\hline 0.8 & 3.3 & 2.9 & 3.1 & 2.2 & 2.1 & 2.1 & 1.5 & 1.6 & 1.6 & 1.5 & 1.5 & 1.5 \\
\hline 0.9 & 2.8 & 2.4 & 2.5 & 1.8 & 1.7 & 1.7 & 1.3 & 1.3 & 1.4 & 1.3 & 1.3 & 1.3 \\
\hline 1.0 & 2.5 & 2.1 & 2.1 & 1.5 & 1.4 & 1.4 & 1.2 & 1.2 & 1.2 & 1.2 & 1.2 & 1.2 \\
\hline 1.1 & 2.2 & 1.8 & 1.8 & 1.3 & 1.3 & 1.3 & 1.1 & 1.1 & 1.1 & 1.1 & 1.1 & 1.1 \\
\hline 1.2 & 2.0 & 1.6 & 1.6 & 1.2 & 1.2 & 1.2 & 1.1 & 1.1 & 1.1 & 1.1 & 1.1 & 1.1 \\
\hline 1.3 & 1.8 & 1.5 & 1.4 & 1.1 & 1.1 & 1.1 & 1.0 & 1.0 & 1.0 & 1.0 & 1.0 & 1.0 \\
\hline 1.4 & 1.6 & 1.4 & 1.3 & 1.1 & 1.1 & 1.1 & 1.0 & 1.0 & 1.0 & 1.0 & 1.0 & 1.0 \\
\hline 1.5 & 1.5 & 1.3 & 1.3 & 1.1 & 1.1 & 1.0 & 1.0 & 1.0 & 1.0 & 1.0 & 1.0 & 1.0 \\
\hline$E A R L_{(0,0.5]}$ & 95.9 & 89.2 & 87.8 & 90.4 & 85.9 & 85.2 & 86.9 & 80.4 & 83.1 & 87.6 & 78.8 & 77.2 \\
\hline$E A R L_{(1,1.5]}$ & 1.8 & 1.5 & 1.5 & 1.2 & 1.1 & 1.1 & 1.1 & 1.1 & 1.1 & 1.0 & 1.0 & 1.0 \\
\hline $\operatorname{EARL}_{(0,1.5]}$ & 33.8 & 31.3 & 30.9 & 31.3 & 29.8 & 29.6 & 29.9 & 27.7 & 28.7 & 30.1 & 27.2 & 26.7 \\
\hline$L_{T}$ & 2.906 & 2.474 & 2.318 & 2.991 & 2.575 & 2.423 & 3.135 & 2758 & 2.624 & 3.12 & 2.75 & 2.623 \\
\hline
\end{tabular}


Table 6. The OOC $A R L$ profile comparison of the EWMA, DEWMA and TEWMA charts with and without FIR features when $(m, n, \lambda)=(100,5,0.5)$ for a nominal $A R L_{0}=500$ under the $\operatorname{GAM}(3,1)$ distribution

\begin{tabular}{|c|c|c|c|c|c|c|c|c|c|c|c|c|}
\hline & \multicolumn{3}{|c|}{ Standard } & \multicolumn{3}{|c|}{ FIR } & \multicolumn{3}{|c|}{ MFIR } & \multicolumn{3}{|c|}{ IMFIR } \\
\hline Shift & EWMA & DEWMA & TEWMA & EWMA & DEWMA & TEWMA & EWMA & DEWMA & TEWMA & EWMA & DEWMA & TEWMA \\
\hline 0.1 & 356.8 & 345.5 & 332.4 & 363.4 & 356.2 & 343.9 & 375.3 & 370.5 & 354.0 & 362.2 & 355.5 & 343.6 \\
\hline 0.2 & 133.3 & 111.3 & 110.0 & 131.8 & 112.7 & 110.0 & 109.5 & 101.3 & 104.8 & 120.8 & 116.6 & 116.5 \\
\hline 0.3 & 31.7 & 30.4 & 27.7 & 35.2 & 24.6 & 24.4 & 25.4 & 20.9 & 21.4 & 31.2 & 24.5 & 21.0 \\
\hline 0.4 & 12.2 & 11.9 & 12.2 & 10.8 & 9.4 & 10.1 & 8.5 & 6.9 & 7.8 & 8.4 & 6.8 & 7.1 \\
\hline 0.5 & 7.5 & 7.0 & 7.6 & 6.1 & 5.5 & 6.0 & 4.0 & 3.8 & 4.2 & 3.9 & 3.8 & 4.2 \\
\hline 0.6 & 5.4 & 4.8 & 5.3 & 4.0 & 3.6 & 3.8 & 2.5 & 2.4 & 2.7 & 2.5 & 2.5 & 2.6 \\
\hline 0.7 & 4.2 & 3.7 & 3.9 & 2.9 & 2.6 & 2.6 & 1.8 & 1.7 & 1.8 & 1.8 & 1.7 & 1.8 \\
\hline 0.8 & 3.4 & 2.9 & 3.0 & 2.1 & 1.9 & 1.9 & 1.4 & 1.3 & 1.4 & 1.4 & 1.3 & 1.3 \\
\hline 0.9 & 2.9 & 2.4 & 2.4 & 1.6 & 1.5 & 1.5 & 1.2 & 1.2 & 1.2 & 1.2 & 1.2 & 1.1 \\
\hline 1.0 & 2.5 & 2.1 & 2.0 & 1.4 & 1.3 & 1.2 & 1.1 & 1.1 & 1.1 & 1.1 & 1.1 & 1.1 \\
\hline 1.1 & 2.2 & 1.8 & 1.7 & 1.2 & 1.1 & 1.1 & 1.0 & 1.0 & 1.0 & 1.0 & 1.0 & 1.0 \\
\hline 1.2 & 2.0 & 1.6 & 1.5 & 1.1 & 1.0 & 1.0 & 1.0 & 1.0 & 1.0 & 1.0 & 1.0 & 1.0 \\
\hline 1.3 & 1.8 & 1.4 & 1.3 & 1.0 & 1.0 & 1.0 & 1.0 & 1.0 & 1.0 & 1.0 & 1.0 & 1.0 \\
\hline 1.4 & 1.7 & 1.3 & 1.2 & 1.0 & 1.0 & 1.0 & 1.0 & 1.0 & 1.0 & 1.0 & 1.0 & 1.0 \\
\hline 1.5 & 1.6 & 1.2 & 1.1 & 1.0 & 1.0 & 1.0 & 1.0 & 1.0 & 1.0 & 1.0 & 1.0 & 1.0 \\
\hline $\operatorname{EARL}_{(0,0.5]}$ & 108.3 & 101.2 & 98.0 & 109.4 & 101.7 & 98.9 & 104.5 & 100.7 & 98.4 & 105.3 & 101.4 & 98.5 \\
\hline$E A R L_{(1,1.5]}$ & 1.9 & 1.5 & 1.4 & 1.1 & 1.0 & 1.0 & 1.0 & 1.0 & 1.0 & 1.0 & 1.0 & 1.0 \\
\hline$E A R L_{(0,1.5]}$ & 37.9 & 35.3 & 34.2 & 37.6 & 35.0 & 34.0 & 35.7 & 34.4 & 33.7 & 36.0 & 34.7 & 33.7 \\
\hline$L_{T}$ & 2.906 & 2.474 & 2.318 & 2.991 & 2.575 & 2.423 & 3.135 & 2758 & 2.624 & 3.12 & 2.75 & 2.623 \\
\hline
\end{tabular}

\section{Illustrative example}

The implementation of the proposed TEWMA $W$ control chart with and without the IMFIR feature using a dataset on the size of piston rings from Montgomery ${ }^{45}$ for which a goodness of fit test for normality is not rejected since the $p$-value is equal to 0.4167 . Setting an $A R L_{0}=500$, we use $\lambda=0.50$ and $L_{T}=2.937$, so that the attained $A R L_{0}$ value of the TEWMA W chart be equal to 500.14 for $(m, n)=(125,5)$. The TEWMA $W$ chart is shown in Figure 6 and no charting statistic plots beyond the control limits, i.e. it does not give a signal in the prospective phase. When the IMFIR feature is incorporated in the TEWMA $W$ chart, it is found that $L_{T}=3.177$ yields an attained $A R L_{0}$ value of 501.22. The IMFIR-TEWMA $W$ chart is also shown in Figure 6 where we observe that it gives a signal on the first sample in the prospective phase. Moreover, it is observed in Figure 6 that, the IMFIR adjustment factor narrows the control limits during the start-up period. This in turn, ensures that the IMFIRTEWMA $W$ chart has a better detection ability than the TEWMA $W$ chart (without the IMFIR feature). Also, it can be seen that, as the time increases, the control limits of the IMFIR-TEWMA $W$ chart converges towards those of the TEWMA $W$ chart without the IMFIR, which shows that the effect of the IMFIR feature is only applicable during start-up only and gradually disappears as time increases. 


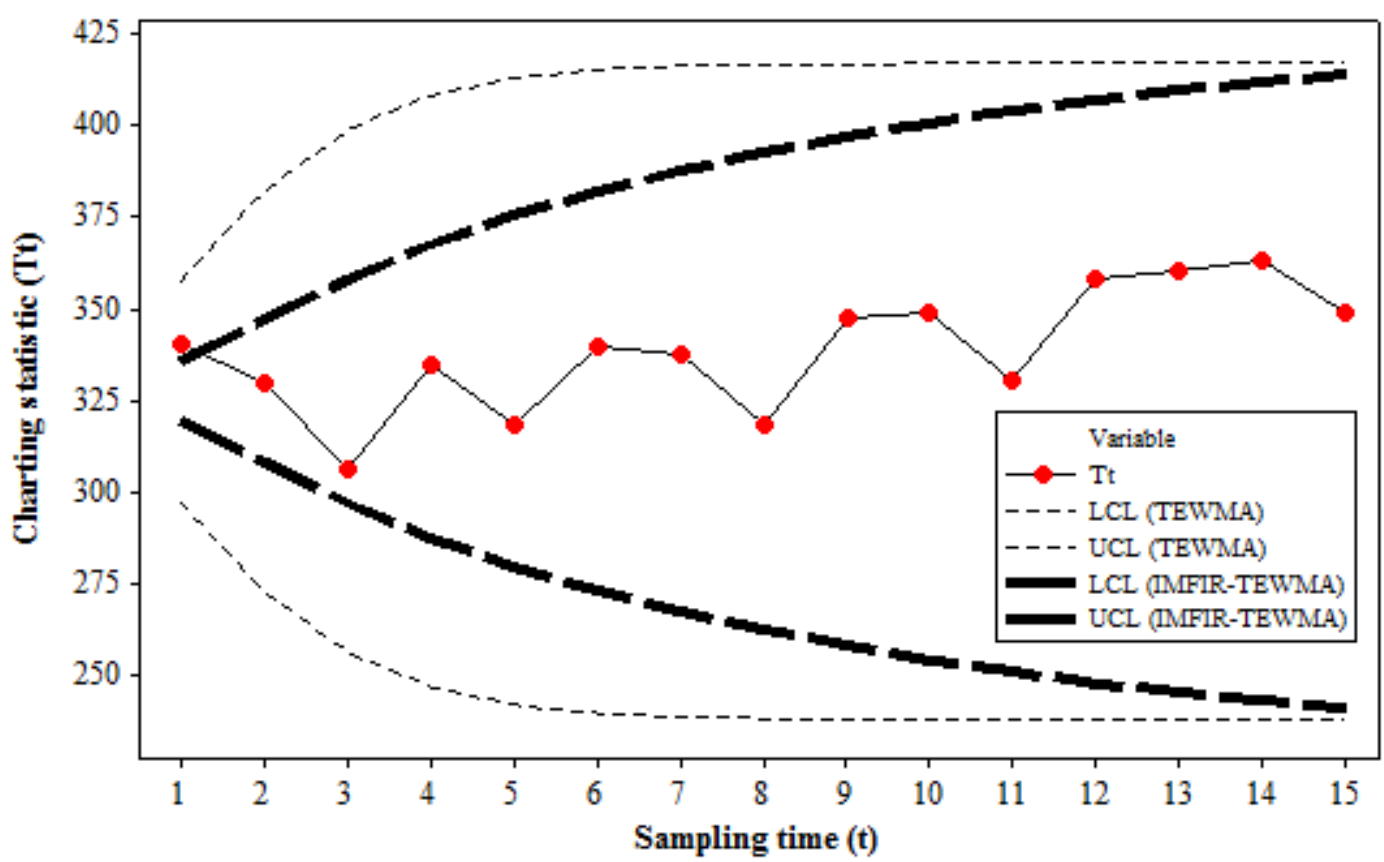

Figure 6. Illustrative example of the standard TEWMA and IMFIR-TEWMA $W$ control charts using the piston ring data from Montgomery ${ }^{45}$

\section{Conclusion}

This paper proposed the TEWMA chart based on the Wilcoxon rank-sum $(W)$ statistic with and without the IMFIR feature. A comparison against other FIR features indicates that the IMFIR feature has the best detection ability for the new TEWMA $W$ chart in most situations. More importantly, the TEWMA chart outperforms the DEWMA and EWMA $W$ charts with and without the FIR features, especially for small shifts. However, the DEWMA $W$ chart has the best performance in detecting moderate shifts. Therefore, it can be said that the proposed TEWMA $W$ chart with IMFIR feature can be used over the DEWMA and EWMA $W$ charts as it is shown that it is more sensitive and results in earlier OOC signals in most situations as compared to its competitors.

For future research, we intend to propose the TEWMA chart to monitor variability using the Ansari-Bradley statistic (refer for instance to Zhou et $\mathrm{al}^{46}$ ) and also study the effect of the IMFIR feature.

\section{Appendix}

With the help of a formal calculus software, $\operatorname{Var}\left(T_{t}\right)$ can equivalently be written as 


$$
\begin{aligned}
& \operatorname{Var}\left(T_{t}\right)=\left(\frac{\lambda^{6}}{4} \sum_{j=1}^{t}(t-j+1)^{2}(t-j+2)^{2}(1-\lambda)^{2(t-j)}\right) \sigma_{W}^{2} \\
&= \frac{1}{(\lambda-2)^{2} \lambda^{5}}\left(\lambda^{8} t^{2}(t+1)^{2}(1-\lambda)^{2 t}-8 \lambda^{7} t^{2}(t+1)^{2}(1-\lambda)^{2 t}\right. \\
&+4 \lambda^{6} t^{2}\left(6 t^{2}+11 t+6\right)(1-\lambda)^{2 t}-8 \lambda^{5} t^{2}\left(4 t^{2}+5 t+4\right)(1-\lambda)^{2 t} \\
&+8 \lambda^{2}\left(6 t^{2}(1-\lambda)^{2 t}-9 t(1-\lambda)^{2 t}+5(1-\lambda)^{2 t}-5\right) \\
&+16 \lambda^{3}\left(2 t^{3}(1-\lambda)^{2 t}-3 t^{2}(1-\lambda)^{2 t}+3 t(1-\lambda)^{2 t}-(1-\lambda)^{2 t}+1\right) \\
&+4 \lambda^{4}\left(4 t^{4}(1-\lambda)^{2 t}-4 t^{3}(1-\lambda)^{2 t}+7 t^{2}(1-\lambda)^{2 t}-3 t(1-\lambda)^{2 t}\right. \\
&\left.+(1-\lambda)^{2 t}-1\right)+24\left((1-\lambda)^{2 t}-1\right) \\
&\left.+48 \lambda\left(t(1-\lambda)^{2 t}-(1-\lambda)^{2 t}+1\right)\right) \sigma_{W}^{2} .
\end{aligned}
$$

Another alternative formulation of the above expression is provided in Alevizakos et $\mathrm{al}^{36}$.

\section{References}

1. Chakraborti S, Graham MA. Nonparametric Statistical Process Control. Wiley, New York, 2019.

2. Roberts SW. Control chart tests based on geometric moving averages. Technometrics, 1959; 1(3):239-250.

3. Page E. Continuous inspection schemes. Biometrika, 1954; 41(1-2):100-115.

4. Sheu S-H, Lin T-C. The generally weighted moving average control chart for detecting small shifts in the process mean. Quality Engineering, 2003; 16(2):209-231.

5. Abbas N. Homogeneously weighted moving average control chart with an application in substrate manufacturing process. Computers \& Industrial Engineering, 2018; 120:460-470.

6. Hawkins DM, Olwell DH. Cumulative Sum Charts and Charting for Quality Improvement. New York: Springer-Verlag, 1998.

7. Ruggeri F, Kenett RS, Faltin FW. Exponentially weighted moving average (EWMA) control chart. In Encyclopaedia of Statistics in Quality and Reliability, 2:633-639, New Jersey, Hoboken: John Wiley\& Sons, 2007.

8. Mabude K., Malela-Majika J-C, Castagliola P, Shongwe SC. Generally weighted moving average monitoring schemes - Overview and Perspectives. Quality and Reliability Engineering International, 2020; DOI: 10.1002/qre.2765.

9. Nawaz T, Han D. Monitoring the process location by using new ranked set sampling-based memory control charts. Quality Technology \& Quantitative Management, 2020; 17(3):255-284.

10. Abid M, Mei S, Nazir HZ, Riaz M, Hussain S. A mixed HWMA-CUSUM mean chart with an application to manufacturing process. Quality and Reliability Engineering International, 2020; DOI: 10.1002 /qre.2752.

11. Adegoke NA, Smith ANH, Anderson MJ, Sanusi RA, Pawley MDM. Efficient homogeneously weighted moving average chart for monitoring process mean using an auxiliary variable. IEEE Access, 7:94021-94032.

12. Adeoti OA, Koleoso SO. A hybrid homogeneously weighted moving average control chart for process monitoring. Quality and Reliability Engineering International, 2020; 36(6):2170-2186.

13. Mukherjee A, Chong ZL, Khoo MBC. Comparisons of some distribution-free CUSUM and EWMA schemes and their applications in monitoring impurity in mining process flotation. Computers \& Industrial Engineering, 2019; 137:106059. 
14. Triantafyllou IS. A new distribution-free control scheme based on order statistics. Journal of Nonparametric statistics, 2019; 31(1):1-30.

15. Chong ZL, Huang S, Mukherjee A, Yang J. Performance comparisons of distribution-free Shewhart-type Lepage and Cucconi schemes in monitoring complex process distributions. Transactions of the Institute of Measurement and Control, 2020; 42(14):2787-2811.

16. Chong ZL, Mukherjee A, Khoo MBC. Some simplified Shewhart-type distribution-free joint monitoring schemes and its application in monitoring drinking water turbidity. Quality Engineering, 2020; 32(1):91-110.

17. Shafqat A, Huang Z, Aslam M, Nawaz MS. A nonparametric repetitive sampling DEWMA control chart based on linear prediction. IEEE Access, 2020; 8:74977-74990.

18. Shamma SE, Shamma AK. Development and evaluation of control charts using double exponentially weighted moving averages. International Journal of Quality \& Reliability Management, 1992; 9(6):18-25.

19. Zhang L, Chen G. An extended EWMA mean chart. Quality Technology \& Quantitative Management, 2005; 2(1):39-52.

20. Hong PE, Kang WH, Kang WC. DEWMA control chart for the coefficient of variation. Journal of Advanced Materials Research, 2011; 203:1682-1688

21. Alkahtani SS. Robustness of DEWMA versus EWMA control charts to non-normal processes. Journal of Modern Applied Statistical Methods, 2013; 12(1):148-163.

22. Teh YS, Khoo MBC, Ong HK, Teoh WL. Comparing the median run length (MRL) performances of the max-EWMA and max-DEWMA control charts for skewed distributions. Proceedings of the 2014 International Conference on Industrial Engineering and Operations Management, Bali, Indonesia, 2014:1080-1087.

23. Chao MK, Tsai FC, Lu LS. (2014). An intelligent GA-nonparametric DEWMA sign chart for green chain management. Proceeding of the 2014 IEEE $18^{\text {th }}$ International Conference, 2014: 247-252.

24. Alevizakos V, Koukouvinos C. Monitoring of zero-inflated binomial processes with a DEWMA control chart. Journal of Applied Statistics, 2020; DOI: 10.1080/02664763.20201761950.

25. Karakani HM, Human SW, Van Niekerk J. A double generally weighted moving average exceedance control chart. Quality and Reliability Engineering International, 2019; 35(1):224245.

26. Li SY, Tang LC, Ng SH. Nonparametric CUSUM and EWMA control charts for detecting mean shifts. Journal of Quality Technology, 2010; 42(2):209-226.

27. Malela-Majika J-C, Rapoo EM. Distribution-free cumulative sum and exponentially weighted moving average control charts based on the Wilcoxon rank-sum statistic using ranked set sampling for monitoring mean shifts. Journal of Statistical Computation and Simulation, 2016; 86(18):3715-3734.

28. Malela-Majika J-C. New distribution-free memory-type control charts based on the Wilcoxon rank-sum statistic. Quality Technology \& Quantitative Management, 2020; DOI: 10.1080/16843703.2020.1753295.

29. Tapang W, Pongpullponsak A, Sarikavanij S. Three nonparametric control charts based on ranked set sampling. Chiang Mai Journal of Science, 2016; 43(4):914-929.

30. Malela-Majika J-C, Rapoo EM. Distribution-free mixed cumulative sum-exponentially weighted moving average control charts for detecting mean shifts. Quality and Reliability Engineering International, 2017; 33(8):1983-2002.

31. Chakraborti S, Graham MA. Nonparametric (distribution-free) control charts: An updated overview and some results. Quality Engineering, 2019; 31(4):523-544.

32. Triantafyllou IS. Wilcoxon-type rank-sum control charts based on progressively censored reference data. Communications in Statistics - Theory and Methods, 2020; DOI: 10.1080/03610926.2019.1634816.

33. Mabude K, Malela-Majika J-C, Shongwe SC. A new distribution-free generally weighted moving average monitoring scheme for detecting unknown mean shifts. International Journal of Industrial Engineering Computations, 2020; 11(2):235-254. 
34. Tercero-Gomez V, Aguilar-Lleyda V, Cordero-Franco A, Conover W. A distribution-free CUSUM chart for joint monitoring of location and scale based on the combination of Wilcoxon and Mood statistics. Quality and Reliability Engineering International, 2020; 36(4):1422-1453.

35. Qiu, P. Introduction to Statistical Process Control. Chapman \& Hall/CRC Press, Taylor \& Francis Group, Baton Rouge: Florida, 2014.

36. Alevizakos V, Chatterjee K, Koukouvinos C. The triple exponentially weighted moving average control chart. Quality Technology \& Quantitative Management, 2020; DOI: 10.1080/16843703.2020.1809063.

37. Alevizakos V, Chatterjee K, Koukouvinos C. A triple exponentially weighted moving average control chart for monitoring time between events. Quality and Reliability Engineering International, 2020; DOI: 10.1002/qre.2781.

38. Lucas JM, Crosier RB. Fast initial response for CUSUM quality control schemes: Give your CUSUM a head start, Technometrics, 1982; 24(3):199-205.

39. Rhoads TR, Montgomery DC, Mastrangelo CM. A fast initial response scheme for the exponentially weighted moving average control chart. Quality Engineering, 1996; 9(2):317-327.

40. Knoth S. Fast initial response features for EWMA control charts. Statistical Papers, 2005; 46(1):47-64.

41. Lu S-L. Applying fast initial response features on GWMA control charts for monitoring autocorrelation data. Communications in Statistics - Theory and Methods, 2016; 45(11):33443356.

42. Steiner SH. EWMA control charts with time-varying control limits and fast initial response. Journal of Quality Technology, 1999; 31(3):75-86.

43. Haq A, Brown J, Moltchanova E. Improved fast initial response features for exponentially weighted moving average and cumulative sum control charts. Quality and Reliability Engineering International, 2014; 30(5):697-710.

44. Wilcoxon F. Individual comparisons by ranking methods. Biometrics Bulletin, 1945; 1(6):80-83.

45. Montgomery DC. Statistical Quality Control: A Modern Introduction, $7^{\text {th }}$ ed., New Jersey, Hoboken: John Wiley \& Sons, 2013.

46. Zhou M, Zhou Q, Geng W. A new nonparametric control chart for monitoring variability. Quality and Reliability Engineering International, 2016; 32(7):2471-2479. 